\title{
Produção de cultivares de alface americana sob dois sistemas de cultivo
}

\author{
Cristian Rafael Brzezinski ${ }^{*}$, Julia Abati ${ }^{1}$, Alexsandro Geller ${ }^{2}$, Flavia Werner $^{l}$, Claudemir Zucareli $^{1}$ \\ $10.1590 / 0034-737 X 201764010012$
}

\section{RESUMO}

A alface é cultivada em todas as regiões brasileiras, porém há restrições ao seu cultivo em virtude de sua sensibilidade às condições adversas de temperatura, umidade do ar e disponibilidade de água. Diante disso, objetivou-se, com este experimento, avaliar a produção de quatro cultivares de alface americana, sob dois sistemas de cultivo. O delineamento experimental utilizado foi o de blocos ao acaso, em esquema de parcelas subdivididas. As parcelas foram constituídas por dois sistemas de cultivo (túnel baixo de polietileno e campo aberto), e, as subparcelas por quatro cultivares de alface americana (Angelina, Rubette, Grandes Lagos 659 e Tainá), com quatro repetições. As características avaliadas foram: altura de plantas, diâmetro total da planta, diâmetro transversal da cabeça, comprimento de caule, diâmetro de caule, massa de matéria fresca de caule, número de folhas comerciais e não comerciais, massa de matéria fresca comercial e não comercial. Foi realizada análise de variância e as médias foram comparadas pelo teste de Tukey. O túnel baixo favorece o crescimento e a produção de cultivares de alface americana, em relação ao campo aberto. O cultivar Rubette mostra crescimento e produção superiores aos demais cultivares avaliados, nos dois sistemas de cultivo.

Palavras-chave: Lactuca sativa L.; túnel baixo; campo aberto; sistemas de produção; folhosas.

\section{ABSTRACT}

\section{Production of iceberg lettuce cultivars under two cropping systems}

The lettuce is grown in all regions of Brazil; however, there are restrictions on its cultivation due to its sensitivity to the adverse conditions of temperature, humidity, and water availability. In this context, the aim of this study was to evaluate the production of four lettuce cultivars under two cropping systems. The experimental design was randomized blocks in a split-plot scheme. The plots consisted of two cropping systems (low polyethylene tunnel and open field) and the sub plots of four lettuce cultivars (Angelina, Rubette, Grandes Lagos 659, and Tainá) with four replications. The characteristics evaluated were: plant height, overall diameter of the plant, transverse head diameter, stem length, stem diameter, stem fresh weight, number of commercial and non-commercial leaves, and commercial and non-commercial fresh weight. Analysis of variance was performed and means were compared by Tukey test. The low tunnel favors the growth and production of lettuce cultivars in relation to open field. Cultivar Rubette shows growth and production superior to the other cultivars in both cropping systems.

Key words: Lactuca sativa L.; low tunnel; open field; cropping systems; leafy vegetable.

\footnotetext{
Submetido em 01/08/2014 e aprovado em 16/08/2016.

${ }^{1}$ Universidade Estadual de Londrina, Centro de Ciências Agrárias, Programa de Pós Graduação em Agronomia, Londrina, Paraná, Brasil. cristian_brzezinski@yahoo.com.br; bff_julia@hotmail.com; fla_werner@hotmail.com; claudemircca@uel.br

${ }^{2}$ Unidade de Ensino Superior Vale do Iguaçu, União da Vitória, Paraná, Brasil. alexsandrogeller@yahoo.com.br

*Autor para correspondência: cristian_brzezinski@yahoo.com.br
} 


\section{INTRODUÇÃO}

A alface (Lactuca sativa L.) é a hortaliça folhosa de maior importância econômica no Brasil, sendo cultivada geralmente em condições de agricultura familiar, de maneira intensiva, em pequenas propriedades situadas em áreas periurbanas ou nos cinturões verdes dos grandes centros urbanos (Costa \& Sala, 2005).

Dentre os diversos grupos de alface, a do tipo americana tem-se destacado por apresentar folhas internas de coloração amarela ou branca, imbricadas e crocantes e, também por suportar melhor o processamento, além de apresentar melhor conservação pós-colheita e resistência ao transporte e manuseio. Graças a essas características é utilizada tanto in natura, como na indústria de processamento mínimo e por redes de "fast food" (Yuri et al., 2002; Henz \& Suinaga, 2009).

Apesar de ser cultivada em todas as regiões brasileiras, há restrições a seu cultivo, em virtude da sensibilidade da alface às condições adversas de temperatura, umidade do ar e precipitação pluvial (Gomes et al., 2005). Condições meteorológicas pouco favoráveis, como baixas temperaturas (inferiores a $10^{\circ} \mathrm{C}$ ) e chuvas prolongadas retardam o seu crescimento e podem danificar as plantas. Por outro lado, elevadas temperaturas do ar (acima de $20^{\circ} \mathrm{C}$ ) e intensa radiação solar favorecem o pendoamento precoce das plantas, podendo provocar queima das bordas das folhas externas, formar cabeças pouco compactas e também contribuir para a ocorrência de deficiência de cálcio conhecida como "tipburn" (Turini et al., 2011).

Por causa dessas limitações da produção em campo aberto, o cultivo protegido vem aumentando em importância (Gualberto et al., 2009; Silva et al., 2014). Segundo Segovia et al. (1997), o cultivo em ambiente protegido é uma técnica para se obter produção alta e de excelente qualidade, em comparação com o obtido em campo aberto, graças às condições de clima mais propícias ao desenvolvimento da cultura ao longo do ciclo.

Dantas \& Escobedo (1998) verificaram que o cultivo de alface em ambiente protegido, tipo túnel, ofereceu melhores condições para o crescimento, desenvolvimento e rendimento da cultura quando comparado com o sistema de cultivo em campo aberto.

Entretanto, para que se obtenha sucesso com o sistema de cultivo adotado, um dos fatores a ser considerado é a escolha do cultivar adequado, já que a manifestação do potencial produtivo da alface depende da interação genótipo x ambiente (Gualberto et al., 2009). Segundo Yuri et al. (2004), os melhores cultivares são aqueles adaptados às condições da região de produção, visto que cada um requer condições especiais de temperatura e fotoperíodo para a obtenção das características qualitativas desejáveis e de produtividade.
Diante do exposto, objetivou-se, com este experimento, avaliar a produção de quatro cultivares de alface americana, sob dois sistemas de cultivo.

\section{MATERIAL E MÉTODOS}

O experimento foi conduzido no inverno (de maio a setembro de 2013), na Área Experimental de Olericultura da Unidade de Ensino Superior Vale do Iguaçu (UNIGUAÇU), localizada no município de União da Vitória, $\mathrm{PR}$, situado nas coordenadas $26^{\circ} 13^{\prime} 48^{\prime \prime} \mathrm{S}$ e $51^{\circ} 5^{\prime} 11^{\prime \prime}$ $\mathrm{O}$, em altitude em torno de $830 \mathrm{~m}$; clima subtropical úmido; temperatura média de $21^{\circ} \mathrm{C}$ e precipitação média anual de $1445 \mathrm{~mm}$. Os dados de temperatura máxima e mínima, bem como a precipitação média para o período de cultivo, são apresentados na Figura 1.

O delineamento experimental utilizado foi o de blocos ao acaso, em esquema fatorial 2 x 4, com parcelas subdivididas. As parcelas foram constituídas por dois sistemas de cultivo (túnel baixo de polietileno e campo aberto), e, as subparcelas por quatro cultivares de alface americana (Angelina, Rubette, Grandes Lagos 659 e Tainá), com quatro repetições.

O túnel baixo foi coberto com tela de polietileno transparente, de baixa densidade, com as dimensões de $0,8 \mathrm{~m}$ de altura e 1,10 m de base. As laterais foram mantidas abertas à altura de $0,30 \mathrm{~m}$ da base, para permitir a circulação do ar. Ambos os sistemas de cultivo apresentaram $30 \mathrm{~m}$ de comprimento.

As subparcelas, em ambos os sistemas de cultivo, foram constituídas de 1,50 m de comprimento por 1,10 m de largura, e comportaram seis linhas transversais, com quatro plantas espaçadas de $0,25 \mathrm{~m}$ cada uma (entre linhas e entre plantas), totalizando 24 plantas por subparcela. Foi considerada como área útil, oito plantas das quatro linhas centrais, deixando-se uma planta nas extremidades de cada linha como bordadura.

A coleta de amostras para análise química foi realizada na camada de 0 a $20 \mathrm{~cm}$, apresentando o solo os seguintes atributos, antes da implantação do experimento: 45,0 $\mathrm{g} \mathrm{dm}^{-3}$ de matéria orgânica; 5,6 de $\mathrm{pH}$ em $\mathrm{CaCl}_{2} ; 12,9 \mathrm{mg} \mathrm{dm}^{-3}$ de P; $0,44 \mathrm{cmol}_{\mathrm{c}} \mathrm{dm}^{-3} \mathrm{de} \mathrm{K} ; 8,3 \mathrm{cmol}_{\mathrm{c}} \mathrm{dm}^{-3} \mathrm{de} \mathrm{Ca} ; 2,1 \mathrm{cmol}_{\mathrm{c}} \mathrm{dm}^{-3} \mathrm{de}$ $\mathrm{Mg}$; e 64\% de saturação da CTC por bases. A adubação da área experimental foi realizada de acordo com os resultados da análise química do solo e o recomendado para a cultura, conforme Trani et al. (1997).

A semeadura da alface foi realizada em bandejas de poliestireno expandido, com 128 células, em substrato comercial Plantmax ${ }^{\circledR}$. As mudas foram produzidas em casa de vegetação, modelo Van der Hoeven ${ }^{\circledR} \mathrm{e}$, a irrigação por aspersão, efetuada de acordo com a necessidade da cultura. As mudas foram transplantadas para a área experimental quando apresentavam em média 4-5 folhas definitivas, ou seja, em torno de 30 dias após a semeadura. 
Foi realizada adubação nitrogenada em cobertura, na dose de $40 \mathrm{~kg} \mathrm{ha}^{-1}$, utilizando-se como fonte a ureia, aos 30 e 45 dias após o transplantio das mudas. A irrigação dos canteiros foi feita por gotejamento, realizada duas vezes ao dia.

O controle de plantas daninhas foi realizado manualmente e não foi necessário realizar o controle de pragas, uma vez que não prejudicaram o desenvolvimento da cultura.

A colheita foi realizada 89 dias após a semeadura, quando as plantas apresentavam as cabeças comerciais compactas. Em seguida, foram realizadas as seguintes avaliações: altura de planta $(\mathrm{cm})$; diâmetro transversal total da planta (folhas baixeiras + cabeça) e diâmetro da parte comercial (cabeça), realizadas com auxílio de um paquímetro, comprimento e diâmetro do caule $(\mathrm{cm})$, massa fresca de caule $(\mathrm{g}$ por planta), número total de folhas comerciais e não comerciais (folhas por planta) e massa fresca comercial e não comercial (kg por planta).

Os dados apresentaram distribuição normal avaliada pelo teste de Shapiro-Wilk. Foi realizada análise de variância e as médias foram comparadas pelo teste de Tukey, a 5\% de probabilidade. As análises foram executadas por meio do programa computacional Sistema para Análise de Variância - SISVAR (Ferreira, 2011).

\section{RESULTADOS E DISCUSSÃO}

Não houve interação significativa entre os fatores avaliados, mostrando que os cultivares responderam da mesma forma aos sistemas de cultivo (Tabela 1). A ausência de interação genótipo x ambiente deve-se aos esforços despendidos pelos programas de melhoramento genético, a fim de propiciar maior estabilidade de produção aos cultivares, em todos os ambientes. Associado a isto, todas as plântulas apresentavam características similares quanto à altura e número de folhas, no momento do transplantio.

Em relação aos efeitos isolados dos sistemas de cultivo, não houve significância sobre o comprimento de caule e número de folhas não comerciais. Já, quanto a cultivares, verificou-se efeito sobre todas as variáveis (Tabela 1).

As plantas produzidas em túnel baixo apresentaram maior altura que as de campo aberto (Tabela 2). Essa diferença entre os sistemas de cultivo pode estar associada ao microclima favorável, proporcionado pelo túnel baixo.

Segundo Edmond et al. (1967), quando uma cultura está sendo conduzida dentro de uma variação ótima de luminosidade, com outros fatores favoráveis, a fotossíntese é elevada e a quantidade de carboidratos utilizados para o crescimento e desenvolvimento da planta é alta. Leite $e t$ al. (2003), ao estudarem a viabilidade de uso de telados para produção de alface em larga escala, relataram que, ao

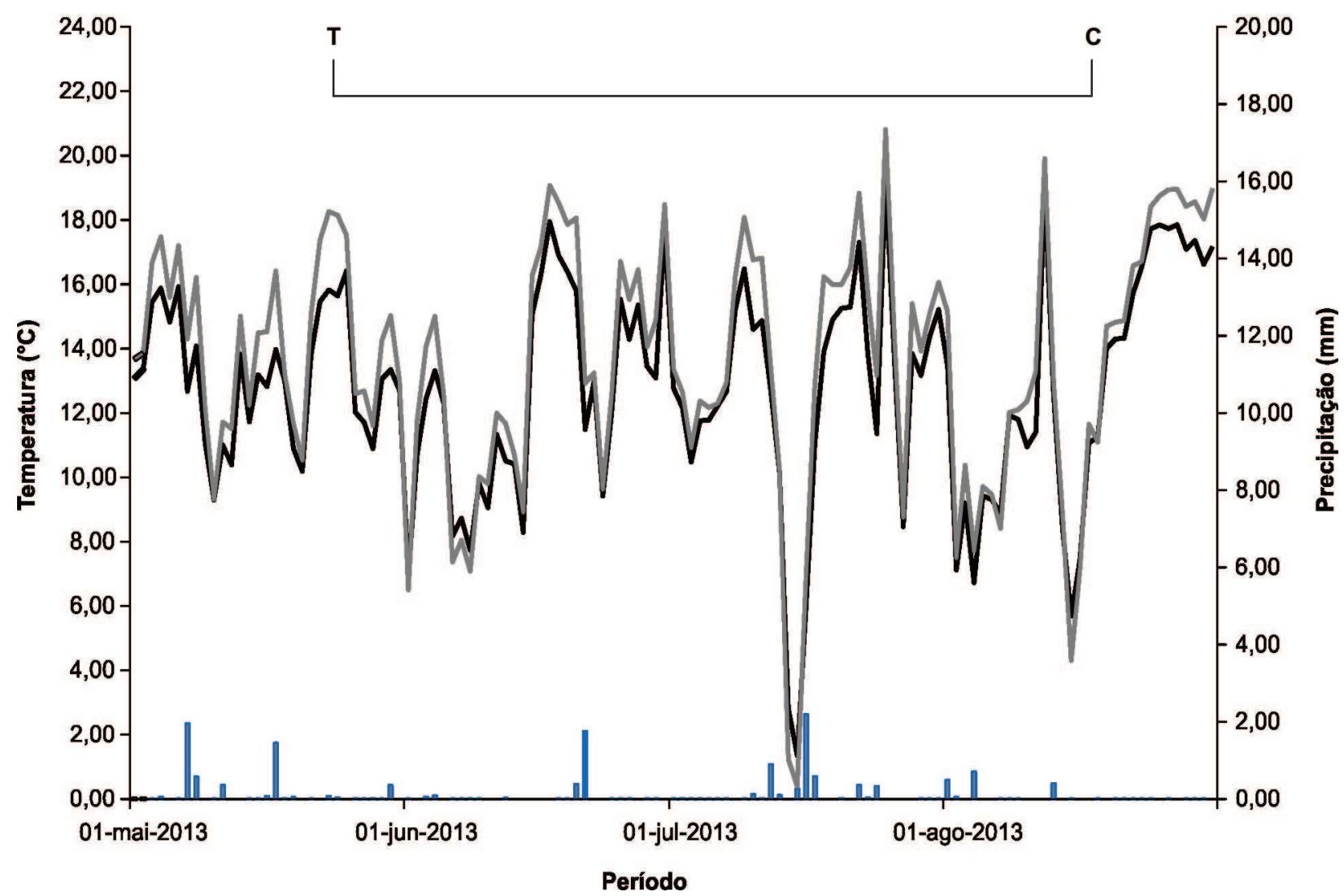

Figura 1: Temperaturas máxima e mínima diárias $\left({ }^{\circ} \mathrm{C}\right)$ e precipitação pluvial (mm), para o período de desenvolvimento da cultura da alface americana. T: transplantio e C: colheita 
longo do desenvolvimento, todas as malhas promoveram altura e diâmetro da planta maiores que os da testemunha (campo aberto). Isso ocorre por causa da maior temperatura ambiental, que afeta o desempenho das plantas em campo aberto, pois os cultivares de alface americana geralmente são sensíveis a temperaturas extremas.

Resultados semelhantes aos observados neste estudo, para a altura de plantas, também foram evidenciados por Queiroga et al. (2001), ao verificarem que os efeitos da temperatura e da luminosidade elevadas podem ser minimizados de forma significativa, quando se utiliza, por exemplo, tela de sombreamento. Segundo os autores, a tela de cor branca (mesma utilizada neste trabalho), associada ao cultivar Grandes Lagos, foi a que proporcionou melhores resultados.
Os cultivares Rubette e Grandes Lagos 659 apresentaram as maiores alturas de plantas (Tabela 3), possivelmente, graças às características genéticas distintas de cada cultivar, em relação ao tamanho médio de plantas.

Para o diâmetro da planta e da cabeça, houve efeitos isolados dos fatores estudados (Tabela 1), sendo que as plantas produzidas em sistema de túnel baixo apresentaram maior diâmetro (planta + cabeça) que os das plantas colhidas em campo aberto (Tabela 2). Segundo Yuri et al. (2002), a alface americana é uma planta tipicamente de inverno, capaz de resistir a baixas temperaturas, inclusive a geadas leves; porém, em condições de temperaturas mais elevadas e de oscilações drásticas, ocorre redução do ciclo da cultura e, consequentemente, menor diâmetro da cabeça. Assim, a diferença constatada no trabalho pode

Tabela 1: Resumo da análise de variância para as características agronômicas avaliadas em quatro cultivares de alface americana (Angelina, Rubette, Grandes Lagos 659 e Tainá), produzidas em dois sistemas de cultivo (túnel baixo e campo aberto)

\begin{tabular}{|c|c|c|c|c|c|c|}
\hline \multirow{2}{*}{ F. V. } & \multirow{2}{*}{ GL } & \multicolumn{5}{|c|}{ Quadrados médios } \\
\hline & & $\mathbf{A P}$ & DTP & DTC & $\mathrm{CC}$ & DC \\
\hline BLOCO & 3 & $1,0483^{\mathrm{ns}}$ & $2,1879^{\mathrm{ns}}$ & $0,3000^{\text {ns }}$ & $0,1358^{\mathrm{ns}}$ & $0,0422^{\mathrm{ns}}$ \\
\hline SISTEMAS & 1 & $100,82 *$ & $135,30 *$ & $24,500 *$ & $0,7688^{\mathrm{ns}}$ & $0,2775^{*}$ \\
\hline ERRO 1 & 3 & 1,810 & 5,174 & 0,813 & 0,227 & 0,020 \\
\hline CULTIVAR & 3 & $24,255^{*}$ & $24,627 *$ & $5,0700 *$ & $5,9153^{*}$ & $0,3745^{*}$ \\
\hline SIST.*CULT. & 3 & $4,0033^{\mathrm{ns}}$ & $2,1079^{\mathrm{ns}}$ & $0,9166^{\mathrm{ns}}$ & $0,3799^{\text {ns }}$ & $0,0463^{\mathrm{ns}}$ \\
\hline ERRO 2 & 18 & 1,745 & 3,080 & 0,286 & 0,182 & 0,014 \\
\hline $\mathrm{CV} 1(\%)$ & & 7,44 & 7,27 & 7,02 & 12,90 & 5,83 \\
\hline CV $2(\%)$ & & 7,31 & 5,61 & 4,17 & 11,55 & 4,94 \\
\hline \multirow[t]{2}{*}{ MÉDIA } & & 18,08 & 31,30 & 12,85 & 3,69 & 2,45 \\
\hline & & MC & NFC & NFNC & MFC & MFNC \\
\hline BLOCO & 3 & $23,083^{\text {ns }}$ & $14,634^{\mathrm{ns}}$ & $0,4700^{\text {ns }}$ & $0,0061^{\mathrm{ns}}$ & $0,0004^{\text {ns }}$ \\
\hline SISTEMAS & 1 & $40,500 * *$ & $102,96^{*}$ & $3,9200^{\text {ns }}$ & $0,1046^{*}$ & $0,0175^{*}$ \\
\hline ERRO 1 & 3 & 1,270 & 1,424 & 1,370 & 0,001 & 0,0001 \\
\hline CULTIVAR & 3 & $2.78,58^{*}$ & $89,857 *$ & $11,863^{*}$ & $0,0380 *$ & $0,0022 *$ \\
\hline SIST.*CULT. & 3 & $19,916^{\mathrm{ns}}$ & $0,8212^{\mathrm{ns}}$ & $2,0566^{\mathrm{ns}}$ & $0,0001^{\mathrm{ns}}$ & $0,0009^{\text {ns }}$ \\
\hline ERRO 2 & 18 & 8,130 & 8,874 & 1,004 & 0,002 & 0,0002 \\
\hline CV $1(\%)$ & & 5,33 & 6,49 & 11,36 & 14,86 & 11,03 \\
\hline CV $2(\%)$ & & 17,82 & 16,21 & 9,73 & 22,05 & 12,79 \\
\hline MÉDIA & & 16,00 & 18,38 & 10,30 & 0,230 & 0,1284 \\
\hline
\end{tabular}

ns, não significativo, ** e ${ }^{*}$, significativo a 1 e $5 \%$ de probabilidade, respectivamente, pelo teste $\mathrm{F}$.

AP: altura de planta; DTP: diâmetro total da planta; DTC: diâmetro transversal da cabeça; CC: comprimento de caule; DC: diâmetro de caule; MC: massa fresca de caule; NFC: número de folhas comerciais; NFNC: número de folhas não comerciais; MFC: massa fresca comercial e MFNC: massa fresca não comercial.

Tabela 2: Médias das características fitométricas avaliadas em plantas de alface americana, em função de dois sistemas de cultivo (túnel baixo e campo aberto)

\begin{tabular}{lcccc}
\hline Sistemas de cultivo & $\begin{array}{c}\text { Altura de planta } \\
(\mathbf{c m})\end{array}$ & $\begin{array}{c}\text { Diâmetro transversal } \\
\text { da planta }(\mathbf{c m})\end{array}$ & $\begin{array}{c}\text { Diâmetro transversal } \\
\text { cabeça }(\mathbf{c m})\end{array}$ & $\begin{array}{c}\text { Diâmetro de caule } \\
(\mathbf{c m})\end{array}$ \\
\hline Túnel baixo & $19,86 \mathrm{a}$ & $33,36 \mathrm{a}$ & $13,72 \mathrm{a}$ & $2,36 \mathrm{~b}$ \\
Campo aberto & $16,31 \mathrm{~b}$ & $29,25 \mathrm{~b}$ & $11,97 \mathrm{~b}$ & $2,54 \mathrm{a}$ \\
\hline CV 1 $(\%)$ & 7,44 & 7,27 & 7,02 & 5,83 \\
\hline
\end{tabular}

Médias seguidas por letras iguais na coluna não diferem entre si pelo teste de Tukey a 5\% de probabilidade.

Rev. Ceres, Viçosa, v. 64, n.1, p. 083-089, jan/fev, 2017 
ter ocorrido em função da amplitude térmica observada no período em que o experimento foi conduzido (Figura 1), pois, para as plantas produzidas em túnel, este efeito pode ter sido minimizado. Na comparação entre cultivares, em ambas as características avaliadas, houve maior diâmetro para as plantas do cultivar Rubette (Tabela 3).

Quanto ao comprimento de caule, as plantas do cultivar Rubette produziram caules com comprimento maior que o das demais (Tabela 3). A característica comprimento do caule é importante na cultura da alface americana, principalmente, quando destinada à indústria de beneficiamento. Ele deve ser bastante reduzido, proporcionando, dessa forma, menores perdas durante o processamento, além de seu efeito na qualidade final do produto, por prejudicar a compacidade da cabeça (Yuri et al., 2002).

O mesmo resultado verificado para o efeito de cultivar no comprimento de caule também foi observado no diâmetro e na massa fresca do caule. Para essas variáveis, foi constatado que as plantas produzidas em túnel baixo apresentaram diâmetro menor e massa maior do que os das plantas colhidas em campo aberto (Tabela 2 e 4).

As plantas de alface americana produzidas em túnel baixo mostraram maior número de folhas comerciais do que as produzidas em campo aberto (Tabela 4). Resultado similar foi obtido por Radin et al. (2004), ao verificarem que plantas de alface comum, cultivadas em estufa, apresentaram um número final de folhas maior do que as cultivadas a campo. Segundo Hermes et al. (2001), em ambiente protegido a temperatura constante pode inferir maior soma de graus dias e provocar aumento do número de folhas. A temperatura constante nesse ambiente possivelmente estimulou e aumentou a velocidade das reações bioquímicas e a translocação da seiva, ocasionando maior crescimento e desenvolvimento da planta (Caliman et al., 2005).

Quando comparados os cultivares, foi constatado que as plantas do cultivar Rubette apresentaram maior número de folhas comerciais (Tabela 5). Porto (1999) verificou que o cultivar Regina destacou-se dos cultivares Grandes Lagos 659 e Tainá quanto ao número de folhas por planta. Essas diferenças observadas para essa característica são devidas, provavelmente, à carga genética de cada cultivar. Para os padrões de comercialização o número de folhas é importante, por determinar se uma planta é viável ou inviável para o consumo in natura, pois as folhas é que serão comercializadas. Segundo Oliveira et al. (2004), na produção de alface a característica número de folhas está intimamente associada à temperatura do ambiente de cultivo e ao fotoperíodo.

Para o número de folhas não comerciais, as plantas do cultivar Angelina apresentaram valores maiores que as demais (Tabela 5), mostrando que essas plantas apresentaram menor qualidade comercial, pois essas folhas são inadequadas para a comercialização (venda in natura).

Quanto às massas de matéria fresca comercial e não comercial, pode ser observado que as plantas produzidas em túnel baixo produziram maior massa de folhas que as produzidas em campo aberto (Tabela 4). Resultado similar foi obtido por Radin et al. (2004), ao verificarem que plan-

Tabela 3: Características fitométricas de quatro cultivares de alface americana, produzidas em dois sistemas de cultivo (túnel baixo e campo aberto)

\begin{tabular}{lccccc}
\hline Cultivares & $\begin{array}{c}\text { Altura de planta } \\
(\mathbf{c m})\end{array}$ & $\begin{array}{c}\text { Diâmetro } \\
\text { transversal da } \\
\text { planta }(\mathbf{c m})\end{array}$ & $\begin{array}{c}\text { Diâmetro } \\
\text { transversal cabeça } \\
(\mathbf{c m})\end{array}$ & $\begin{array}{c}\text { Comprimento } \\
\text { caule }(\mathbf{c m})\end{array}$ & $\begin{array}{c}\text { Diâmetro de caule } \\
(\mathbf{c m})\end{array}$ \\
\hline Angelina & $16,60 \mathrm{~b}$ & $29,85 \mathrm{~b}$ & $12,20 \mathrm{~b}$ & $3,18 \mathrm{~b}$ & $2,38 \mathrm{~b}$ \\
Rubette & $20,27 \mathrm{a}$ & $33,85 \mathrm{a}$ & $14,00 \mathrm{a}$ & $4,94 \mathrm{a}$ & $2,77 \mathrm{a}$ \\
Grandes Lagos & $18,70 \mathrm{a}$ & $30,60 \mathrm{~b}$ & $12,47 \mathrm{~b}$ & $3,57 \mathrm{~b}$ & $2,33 \mathrm{~b}$ \\
Tainá & $16,77 \mathrm{~b}$ & $30,92 \mathrm{~b}$ & $12,72 \mathrm{~b}$ & $3,07 \mathrm{~b}$ & $2,31 \mathrm{~b}$ \\
\hline CV 2 $(\%)$ & 7,31 & 5,61 & 4,17 & 11,55 & 4,94 \\
\hline
\end{tabular}

Médias seguidas por letras iguais na coluna não diferem entre si pelo teste de Tukey a 5\% de probabilidade.

Tabela 4: Desempenho agronômico avaliado em plantas de alface americana produzidas em dois sistemas de cultivo (túnel baixo e campo aberto)

\begin{tabular}{lcccc}
\hline Sistema de cultivo & $\begin{array}{c}\text { Massa de matéria } \\
\text { fresca de caule } \\
\text { (g por planta) }\end{array}$ & $\begin{array}{c}\text { Número de folhas } \\
\text { comerciais }\end{array}$ & $\begin{array}{c}\text { Massa de matéria } \\
\text { fresca comercial } \\
\text { (kg por planta) }\end{array}$ & $\begin{array}{c}\text { Massa de matéria } \\
\text { fresca não comercial } \\
\text { (kg por planta) }\end{array}$ \\
\hline Túnel baixo & $17,12 \mathrm{a}$ & $20,17 \mathrm{a}$ & $0,288 \mathrm{a}$ & $0,1510 \mathrm{a}$ \\
Campo aberto & $14,87 \mathrm{~b}$ & $16,58 \mathrm{~b}$ & $0,173 \mathrm{~b}$ & $0,1058 \mathrm{~b}$ \\
\hline CV 1 (\%) & 5,33 & 6,49 & 14,86 & 11,03 \\
\hline
\end{tabular}

Médias seguidas por letras iguais na coluna não diferem entre si pelo teste de Tukey a 5\% de probabilidade. 
tas de alface produzidas em ambiente protegido apresentaram maior massa de matéria fresca do que as produzidas a campo. As plantas do cultivar Rubette apresentaram maior massa de matéria fresca comercial. Já para a massa de matéria fresca não comercial, somente os cultivares Rubette e Tainá diferiram estatisticamente entre si, com menor valor para o cultivar Tainá (Tabela 5).

Diante dos resultados, verificou-se que o cultivo em túnel baixo propiciou melhor desempenho produtivo que aquele a campo aberto, possivelmente, graças ao microclima favorável, que modificou a temperatura e umidade relativa do ar, a radiação solar e a velocidade do vento, influenciando no desenvolvimento e no crescimento da cultura no interior do túnel (Rebouças et al., 2015). Espécies vegetais, como alface, que necessitam de temperaturas mais amenas para o seu desenvolvimento, sofrem com a alta radiação e temperaturas elevadas, que podem comprome- ter cerca de $25 \%$ da sua produtividade final (Rocha, 2000). Seabra Júnior et al. (2010) avaliaram o desempenho agronômico de cinco cultivares de alface, em diferentes ambientes, e constataram que as temperaturas aferidas para o campo aberto foram sempre maiores que as aferidas em ambientes telados, o que, consequentemente, acarretou menor produção, no caso deste trabalho. Segovia et al. (1997) constataram que a produção de alface em ambiente protegido é uma alternativa eficiente para se obter uma maior regularidade de produção ao longo do ano.

Quanto aos cultivares, Rubette foi o que mostrou melhores resultados para as características avaliadas, provavelmente, graças à maior capacidade de adaptação aos diferentes ambientes de cultivo. Com isso, constata-se a importância da escolha do cultivar adequado, para o sucesso do sistema de cultivo adotado (Gualberto et al., 2009).

Tabela 5: Desempenho agronômico de quatro cultivares de alface americana produzidas em dois sistemas de cultivo (túnel baixo e campo aberto)

\begin{tabular}{lccccc}
\hline Cultivares & $\begin{array}{c}\text { Massa de matéria } \\
\text { fresca fresca } \\
\text { de caule } \\
\text { (g por planta) }\end{array}$ & $\begin{array}{c}\text { Número de folhas } \\
\text { comerciais }\end{array}$ & $\begin{array}{c}\text { Número de folhas } \\
\text { não comerciais }\end{array}$ & $\begin{array}{c}\text { Massa de matéria } \\
\text { fresca comercial } \\
\text { (kg por planta) }\end{array}$ & $\begin{array}{c}\text { Massa de matéria } \\
\text { fresca não } \\
\text { comercial } \\
\text { (kg por planta) }\end{array}$ \\
\hline Angelina & $13,37 \mathrm{~b}$ & $15,30 \mathrm{~b}$ & $12,10 \mathrm{a}$ & $0,175 \mathrm{~b}$ & $0,1287 \mathrm{ab}$ \\
Rubette & $24,75 \mathrm{a}$ & $23,15 \mathrm{a}$ & $9,47 \mathrm{~b}$ & $0,326 \mathrm{a}$ & $0,1487 \mathrm{a}$ \\
Grandes Lagos & $14,00 \mathrm{~b}$ & $17,40 \mathrm{~b}$ & $9,65 \mathrm{~b}$ & $0,233 \mathrm{~b}$ & $0,1287 \mathrm{ab}$ \\
Tainá & $11,87 \mathrm{~b}$ & $17,67 \mathrm{~b}$ & $9,97 \mathrm{~b}$ & $0,188 \mathrm{~b}$ & $0,1075 \mathrm{~b}$ \\
\hline CV 2 (\%) & 17,82 & 16,21 & 9,73 & 22,05 & 12,79 \\
\hline
\end{tabular}

Médias seguidas por letras iguais na coluna não diferem entre si pelo teste de Tukey a 5\% de probabilidade.

\section{CONCLUSÕES}

O sistema de cultivo em túnel baixo favorece o crescimento e a produção de cultivares de alface americana, mais do que o sistema em campo aberto.

O cultivar Rubette mostra crescimento e produção superiores aos demais cultivares avaliados, nos dois sistemas de cultivo.

\section{REFERÊNCIAS}

Caliman FRB, Silva DJH, Fontes PCR, Stringheta PC, Moreira GR \& Cardoso AA (2005) Avaliação de genótipos de tomateiro cultivados em ambiente protegido e em campo nas condições edafoclimáticas de Viçosa. Horticultura Brasileira, 23:255-259.

Costa CP da \& Sala FC (2005) A evolução da alfacicultura brasileira. Horticultura Brasileira, 23. (artigo de capa).

Dantas RT \& Escobedo JF (1998) Índices morfo-fisiológicos e rendimento da alface (Lactuca sativa $\mathrm{L}$.) em ambientes natural e protegido. Revista Brasileira de Engenharia Agrícola e Ambiental, 2:27-31.

Edmond JB, Senn TL \& Andrews ES (1967) Princípios de horticultura. México, Continental. 575p.
Ferreira DF (2011) Sisvar: a computer statistical analysis system. Ciência e Agrotecnologia, 35:1039-1042.

Gomes TM, Modolo VA, Botrel TA \& Oliveira RF (2005) Aplicação de $\mathrm{CO}_{2}$ via água de irrigação na cultura da alface. Horticultura Brasileira, 23:316-319.

Gualberto R, Oliveira PS \& Guimarães A (2009) Adaptabilidade e estabilidade fenotípica de cultivares de alface do grupo crespa em cultivo hidropônico. Horticultura Brasileira, 27:07-11.

Henz GP \& Suinaga F (2009) Tipos de alface cultivados no Brasil. Brasília, Embrapa Hortaliças. 7p. (Comunicado Técnico, 75).

Hermes CC, Medeiros SLP, Manfron PA, Caron B, Pommer SF \& Bianchi C (2001) Emissão de folhas de alface em função de soma térmica. Revista Brasileira de Agrometeorologia, 9:269-275.

Leite CA, Fagnani MA, Tamaoka F \& Silva IJO (2003) Viabilidade do uso de telados para a produção de alface em larga escala. Horticultura brasileira, 21:CD-ROM.

Oliveira ACB, Sediyama MAN, Pedrosa MW, Garcia NCP \& Garcia SLR (2004) Divergência genética e descarte de variáveis em alface cultivada sob sistema hidropônico. Acta Scientiarum Agronomy, 26:211-217.

Porto VCN (1999) Cultivares de alface em sistema solteiro e consorciado com cenoura sob temperatura e luminosidade elevadas. Dissertação de Mestrado. Escola Superior de Agricultura de Mossoró, Mossoró. 40p. 
Queiroga RCF, Bezerra Neto F, Negreiros MZ, Oliveira AP \& Azevedo CMSA (2001) Produção de alface em função de cultivares e tipos de tela de sombreamento nas condições de Mossoró. Horticultura Brasileira, 19:324-328.

Radin B, Reisser Júnior C, Matzenauer R \& Bergamaschi H (2004) Crescimento de cultivares de alface conduzidas em estufa e a campo. Horticultura Brasileira, 22:178-181.

Rebouças PM, Dias IF, Alves MA \& Barbosa Filho JAD (2015) Radiação solar e temperatura do ar em ambiente protegido. Revista Agrogeoambiental, 7:115-125.

Rocha RCC (2000) Tipos e alturas de sombrites na produção de alface sob temperatura e luminosidade elevadas. Dissertação de Mestrado. Escola Superior de Agricultura de Mossoró, Mossoró. $73 \mathrm{p}$

Seabra Junior S, Souza SBS, Neves LG, Theodoro VCA, Nunes MCM, Nascimento AS, Rampazzo R, Luz AO \& Leão LL (2010) Desempenho de cultivares de alface tipo crespa sob diferentes telas de sombreamento no período de inverno. Horticultura Brasileira, 28:252-259.
Segovia JFO, Andriolo JL, Buriol GA \& Schneider FM (1997) Comparação do crescimento e desenvolvimento da alface (Lactuca sativa L.) no interior e exterior de uma estufa de polietileno em Santa Maria - RS. Ciência Rural, 27:33-45.

Silva BA, Silva AR da \& Pagiuca LG (2014) Cultivo protegido: em busca de mais eficiência produtiva. Hortifruti Brasil, 1:10-18.

Trani PE, Passos FA \& Azevedo Filho JA (1997) Recomendação de adubação e calagem para o estado de São Paulo. In: Raij van B, Catnarela H, Quaggio JA \& Furlani AMC (Eds.) Campinas, Hortaliças. p.157-169.

Turini T, Cahn M, Cantwell M, Jackson L, Koike S, Natwick E, Smith R, Subarrao K \& Takele E (2011) Iceberg lettuce production in California. Disponível em: <http://anrcatalog.ucdavis.edu/ pdf/7215.pdf >. Acessado em: 31 de março de 2014.

Yuri JE, Souza RJ de, Freitas SAC de, Rodrigues Júnior JC \& Mota JH (2002) Comportamento de cultivares de alface tipo americana em Boa Esperança. Horticultura Brasileira, 20:229-232.

Yuri JE, Resende GM, Mota JH, Souza RJ, Freitas SAC \& Rodrigues Junior JC (2004) Comportamento de cultivares de alface americana em Santana da Vargem. Horticultura Brasileira, 22:249252 . 